\title{
The association between carbon dioxide, cerebral blood flow, and autoregulation in the premature infant
}

\author{
Suma Bhat Hoffman $\left(10^{1} \cdot\right.$ Anisa Lakhani ${ }^{1} \cdot$ Rose Marie Viscardi ${ }^{1}$ \\ Received: 6 April 2020 / Revised: 24 August 2020 / Accepted: 18 September 2020 / Published online: 8 October 2020 \\ (c) The Author(s), under exclusive licence to Springer Nature America, Inc. 2020
}

\begin{abstract}
Objective Evaluate the association between carbon dioxide $\left(\mathrm{pCO}_{2}\right)$, cerebral blood flow $(\mathrm{CBF})$, and cerebral autoregulation (CA) in preterm infants.

Study design Cerebral saturations ( $\mathrm{rScO}_{2}$, surrogate for $\mathrm{CBF}$ using NIRS) and mean arterial blood pressure (MAP) monitored for $96 \mathrm{~h}$ in infants $<29$ weeks gestation. Relationship between $\mathrm{rScO}_{2}$, the $\mathrm{rScO}_{2}-\mathrm{MAP}$ correlation $(\mathrm{CA}$ analysis) and $\mathrm{pCO}_{2}$ category assessed by mixed effects modeling.

Results Median $\mathrm{pCO}_{2}$ differed by postnatal day $(p<0.0001)-\mathrm{pCO}_{2}$ increased between day 1 and 2, and low variability seen on day 4. A $5 \%$ increase in $\mathrm{rScO}_{2}$ was noted when $\mathrm{pCO}_{2}$ was $>55 \mathrm{mmHg}$ on each postnatal day $(p<0.001)$. No association observed between the overall $\mathrm{rScO}_{2}-\mathrm{MAP}$ correlation and $\mathrm{pCO}_{2}$. On day 1 only, the correlation coefficient decreased from 0.26 to -0.09 as $\mathrm{pCO}_{2}$ category increased $(p=0.02)$.

Conclusions $\mathrm{CBF}$ increased above a $\mathrm{pCO}_{2}$ threshold of $55 \mathrm{mmHg}$, but overall, no association between $\mathrm{pCO}_{2}$ and $\mathrm{CA}$ was noted.
\end{abstract}

\section{Introduction}

Premature infants are likely to require respiratory support and are at risk of fluctuations in partial pressure of carbon dioxide $\left(\mathrm{pCO}_{2}\right)$ levels. Given that $\mathrm{pCO}_{2}$ is a known mediator of cerebral blood flow, these ventilatory driven fluctuations may have significant effects on cerebral hemodynamics. $\mathrm{pCO}_{2}$ reactivity defined as the increase in cerebral blood flow in relation to an increase in $\mathrm{pCO}_{2}$ has been previously demonstrated in premature infants. An increase in $1 \mathrm{KPa}(7.5 \mathrm{mmHg})$ has been shown to increase cerebral blood flow by $\sim 11 \%$ [1]. $\mathrm{pCO}_{2}$ reactivity may be attenuated by day of life with cerebral blood flow increasing in response to a rise in $\mathrm{pCO}_{2}$, but only after the first day of life $[2,3]$. In addition, a $\mathrm{pCO}_{2}$ greater than $50 \mathrm{mmHg}$ may represent a threshold above which cerebral blood flow is increased [2].

Suma Bhat Hoffman

sbhoffman@childrensnational.org

1 Department of Pediatrics, University of Maryland Baltimore, School of Medicine, Baltimore, MD, USA
Cerebral autoregulation (CA), the protective mechanism that maintains stable cerebral blood flow despite fluctuating cerebral perfusion pressures, is often impaired in preterm infants $[4,5]$ in association with both brain injury and death $[4,6,7]$. Though there is no direct means to assess cerebral blood flow in preterm infants, near infrared spectroscopy (NIRS) has been used as a surrogate marker assuming stable oxygenation and metabolic demand [8]. A high level of cerebral oxygenation $\left(\mathrm{rScO}_{2}\right)$ and mean arterial blood pressure (MAP) correlation is suggestive of impaired CA [8-10]. Although $\mathrm{pCO}_{2}$ reactivity has been observed in premature infants, the relationship between $\mathrm{pCO}_{2}$ reactivity and $\mathrm{CA}$ is less clear. A positive correlation between cerebral blood flow and blood pressure has been demonstrated in preterm infants as pCO2 increased, with a cut point greater than a $\mathrm{pCO}_{2}$ of $45-50 \mathrm{mmHg}[2,11]$. It also has been noted that during periods of low blood pressure, $\mathrm{pCO}_{2}$ reactivity may be attenuated [1], suggesting a complex relationship that has not been fully elucidated in this population.

Given the limited information regarding $\mathrm{pCO}_{2}$, cerebral blood flow, and CA, our aim was to further describe these relationships in a larger cohort of premature infants with serial $\mathrm{pCO}_{2}$ measurements over the first 4 days of life. The goal of this study is to help guide ventilatory management 
and allow clinicians to target $\mathrm{pCO}_{2}$ levels that will result in optimal cerebral hemodynamics.

\section{Methods}

\section{Population and data collection}

This is a secondary exploratory analysis of a prospectively enrolled cohort study of subjects $24^{0}-29^{6}$ weeks gestation admitted to the University of Maryland Medical Center level IV neonatal intensive care unit (NICU) between June 2013 and September 2016 who had continuous intra-arterial blood pressure monitoring within the first $12 \mathrm{~h}$ of life [4]. Exclusion criteria including major congenital anomalies, or less than $12 \mathrm{~h}$ of monitoring. The University of Maryland Medical Center Institutional Review Board approved the study, and parental consent was obtained. Demographic and clinical data were obtained from the medical record for each patient.

\section{Continuous data monitoring and processing}

Cerebral saturations were evaluated with the NIRS device (INVOS 5100C, Covidien, Mansfield, MA) within $12 \mathrm{~h}$ of life and continued for a maximum of $96 \mathrm{~h}$ or until the intraarterial line was removed. MAP was continuously monitored by the use of an indwelling umbilical or peripheral arterial catheter. Data were continuously recorded and timesynchronized every $30 \mathrm{~s}$ using a data aggregation device (Vital Sync, Covidien, Mansfield, MA). The data were retrospectively reviewed and artifacts in MAP and $\mathrm{rScO}_{2}$ such as those due to blood sampling and movement were removed manually prior to analysis. Time periods with significant hypoxemia, $\mathrm{SpO}_{2}<80 \%$, were removed from analysis according with previous methodology $[4,6]$.

\section{Carbon dioxide measurements}

$\mathrm{pCO}_{2}$ measured in $\mathrm{mmHg}$ were sampled from the indwelling arterial line and obtained at a minimum of every $12 \mathrm{~h}$ and as clinically indicated. Each measurement was time stamped and recorded with the above physiologic data. $\mathrm{pCO}_{2}$ measurements were evaluated as both continuous and categorical variables. The categories included $<35 \mathrm{mmHg}$, 35-45 mmHg, 46-55 mm Hg, and >55 mmHg, corresponding to values generally considered low, normal, permissive hypercapnia, and high respectively.

\section{Statistical analysis}

Statistical analysis was performed using SAS V.9.4 software (SAS Institute). Continuous data are presented as mean \pm standard deviation or median (range) depending on the distribution. Categorical data are presented as number $(\%)$. Univariate analysis determined the distribution of $\mathrm{pCO}_{2}$ for the overall cohort and then further stratified by postnatal day. Median $\mathrm{pCO}_{2}$ values between postnatal day were compared using Kruskal-Wallis testing.

CA was assessed by dividing the study period into 10min contiguous epochs with time of birth as time zero. For each epoch, the Pearson's correlation coefficient between MAP and $\mathrm{rScO}_{2}$ was calculated $(r)$. Only epochs with concurrent recorded $\mathrm{pCO}_{2}$ measurements were evaluated. Generally, a higher correlation, $r>0.3-0.5$, signifies a more impaired autoregulatory state.

To determine the effect of $\mathrm{pCO}_{2}$ on cerebral blood flow and CA, linear mixed effect modeling was used to account for repeated measures and within patient clustering. Separately, $\mathrm{rScO}_{2}$ (a surrogate marker of cerebral blood flow) was compared with the correlation coefficient between MAP and $\mathrm{rScO}_{2}(r)$ for $\mathrm{pCO}_{2}$ categories and a priori controlling for day of life, gestational age, ventilator mode, and mean airway pressure at the time of sampling. Clustering by subject with random intercept and an unstructured covariance model was used. Additional confounders (presence of a patent ductus arteriosis, vasopressor support, intraventricular hemorrhage, gender, etc.) were assessed in the model based on biologic plausibility and if $p<0.1$ in bivariate analysis and were retained if the estimates were affected by more than $10 \%$.

\section{Results}

All sixty-one subjects from the original cohort were included in the analysis. Demographic and clinical data of this cohort is shown in Table 1. The median hour of life of enrollment was $8 \mathrm{~h}$ (range $4-12 \mathrm{~h}$ ). Twenty-six percent of subjects were enrolled within $6 \mathrm{~h}$ of life. The mean birth weight was $849 \pm 234 \mathrm{~g}$, the mean gestational age was 26.3 \pm 1.6 weeks, and $32(52 \%)$ were male. For the overall cohort, 6 subjects $(10 \%)$ never received invasive respiratory support, 22 (36\%) were supported on conventional mechanical ventilation, and $33(54 \%)$ received high frequency ventilation.

\section{$\mathrm{pCO}_{2}$ data}

During the study timeframe, 1149 arterial blood gas measurements were obtained with corresponding autoregulation data, ranging from 3-43 measurements per subject. Carbon dioxide measurements ranged from 17 to $100 \mathrm{mmHg}$. There were 265 observations on day of life 1, 309 on day 2, 274 on day 3, and 301 observations on day of life 4. A histogram of $\mathrm{pCO}_{2}$ distribution shown in Fig. 1a is notable for a 
Table 1 Demographic and clinical variables.

\begin{tabular}{ll}
\hline Population characteristic & $\begin{array}{l}\text { Study population } \\
(n=61)\end{array}$ \\
\hline Gestational age (weeks), mean \pm SD & $26.3 \pm 1.6$ \\
Birth weight (g), mean \pm SD & $849 \pm 234$ \\
Male gender, $n(\%)$ & $32(52 \%)$ \\
Apgar 5 min, median (range) & $7(1-10)$ \\
Chorioamnionitis, $n(\%)$ & $6(10)$ \\
Type of ventilation support, $n(\%)$ & \\
None/LFNC & $0(0)$ \\
HFNC/CPAP & $6(10)$ \\
Conventional ventilator & $22(36)$ \\
High-frequency venitlation & $33(54)$ \\
Vasopressor use, $n(\%)$ & $22(36)$ \\
IVH, $n(\%)$ & $25(41)$ \\
Grade 3 or 4 IVH, $n(\%)$ & $7(11)$ \\
NEC, $n(\%)$ & $6(10)$ \\
Death, $n(\%)$ & $10(16)$ \\
BPD $n=54, n(\%)$ & $43(72)$ \\
ROP $n=51, n(\%)$ & $35(58)$ \\
\hline
\end{tabular}

rightward skew and a peak between 40 and $50 \mathrm{mmHg}$. The range and number of $\mathrm{pCO}_{2}$ values for each subject is shown in Fig. 1b. There was a significant difference in the median $\mathrm{pCO}_{2}$ by postnatal day $(p<0.0001$, Fig. 2$)$ with the largest increase noted between day 1 (median $40 \mathrm{mmHg}$, range $17-92 \mathrm{mmHg}$ ) and day 2 (median $46 \mathrm{mmHg}$, range 25-92 $\mathrm{mmHg}$ ) of life, and the least variability on day 4 (median $48 \mathrm{mmHg}$, range $26-81 \mathrm{mmHg}$ ).

\section{$\mathrm{pCO}_{2}$ reactivity and $\mathrm{CA}$ by $\mathrm{pCO}_{2}$ category}

Using cerebral saturations as a surrogate marker of cerebral blood flow, generally $\mathrm{rScO}_{2}$ remained stable at $70 \%$ until $\mathrm{pCO}_{2}$ exceeded $55 \mathrm{mmHg}$, and after which an $\mathrm{rScO}_{2}$ increased by $5 \%$. This increase was significant $(p<0.001)$ when compared to all other $\mathrm{pCO}_{2}$ categories, and controlling for postnatal day, gestational age, vasopressor use, respiratory support, and mean airway pressure at the time of sampling using mixed effects modeling (Fig. 3). Postnatal day, gestational age, and mean airway pressure were significant confounders in the model $(p<0.05)$. When stratifying by day of life, a significant increase in $\mathrm{rScO}_{2}$ when $\mathrm{pCO}_{2}$ was greater than $55 \mathrm{mmHg}$ was observed on each of the first 4 days of life.

Examining the effect of $\mathrm{CA}$ and $\mathrm{pCO}_{2}$ we noted that the lowest $\mathrm{pCO}_{2}$ category had the highest correlation coefficient $(r)$ between $\mathrm{MAP}-\mathrm{rScO}_{2}$ of $0.16 \pm 0.4$, followed by a decrease to 0.06 in the higher $\mathrm{CO}_{2}$ categories (Fig. 4). None of these differences was statistically significant after controlling for potential covariates. When stratifying by day of life, there was a decrease in the MAP- $\mathrm{rScO}_{2}$ correlation from $0.26 \pm 0.36$ in the lowest $\mathrm{CO}_{2}$ category to $-0.09 \pm$ 0.38 in the highest $\mathrm{CO}_{2}$ category on day of life 1 . This difference was significant, $p=0.02$, when controlling for gestational age, vasopressor exposure, respiratory support and mean airway pressure at the time of sampling. There was no significant effect of $\mathrm{CO}_{2}$ on the MAP-rScO 2 correlation on any subsequent day.

\section{Discussion}

In this study of premature infants born less than 29 weeks gestation, we evaluated the association of carbon dioxide measurements and CA and blood flow. We found that cerebral saturations, a surrogate marker for cerebral blood flow, increased significantly when $\mathrm{pCO}_{2}$ was greater than $55 \mathrm{mmHg}$ on each day in the first 4 days of life. However, we noted no significant association between $\mathrm{pCO}_{2}$ levels and $\mathrm{CA}$ except on day of life 1 , where low $\mathrm{pCO}_{2}$ values were more likely to be associated with a higher $\mathrm{MAP}-\mathrm{rScO}{ }_{2}$ correlation. To our knowledge, this is the first study to assess the association of $\mathrm{pCO}_{2}$ and $\mathrm{CA}$ in this population using correlation analysis in the time domain. This type of analysis targets slow frequency waves thought to be associated with autoregulatory activity [12].

Similar to previous studies, we noted that $\mathrm{rScO}_{2}$ was positively associated with $\mathrm{pCO}_{2}$, especially above values of $55 \mathrm{mmHg}[2,3]$. In contrast to these previous studies, we noted this association on all postnatal days evaluated, including day 1 . This may be secondary to our larger numbers allowing for increased power to detect these changes. These data underscore the need for tight control of $\mathrm{pCO}_{2}$ levels, especially in the first days of life of infants are more prone to brain injury [13-15]. In this study, we demonstrate significant variability in $\mathrm{pCO}_{2}$ levels in this timeframe when premature infants are at the highest risk for ischemic-reperfusion injury. Permissive hypercapnia, a lung-sparing practice allowing higher $\mathrm{pCO}_{2}$ concentrations [16-19], is often utilized in the care of preterm infants. Generally, during permissive hypercapnia, $\mathrm{pCO}_{2}$ is maintained between 40 and $55 \mathrm{mmHg}$ and has not been associated with increased incidence of brain injury at these levels $[18,19]$. Caution should be taken to avoid extremes of $\mathrm{pCO}_{2}$ as $\mathrm{pCO}_{2}$ levels higher than $55 \mathrm{mmHg}$ in conjunction with a high variability in $\mathrm{pCO}_{2}$ may lead to reperfusion injury.

The observations of an overall lack of association between autoregulation and $\mathrm{pCO}_{2}$ concentrations and an inverse association between $\mathrm{pCO}_{2}$ and impaired $\mathrm{CA}$ on day of life differ from previous studies. Previously, two studies have shown impaired $\mathrm{CA}$ or a trend toward impaired $\mathrm{CA}$ once $\mathrm{pCO}_{2}$ concentrations were greater than $45-50 \mathrm{mmHg}$ 
Fig. 1 Distribution of $\mathrm{pCO}_{2}$ during the entire monitoring period (a) and the number and range of $\mathrm{pCO}_{2}$ measurements for each subject (b).
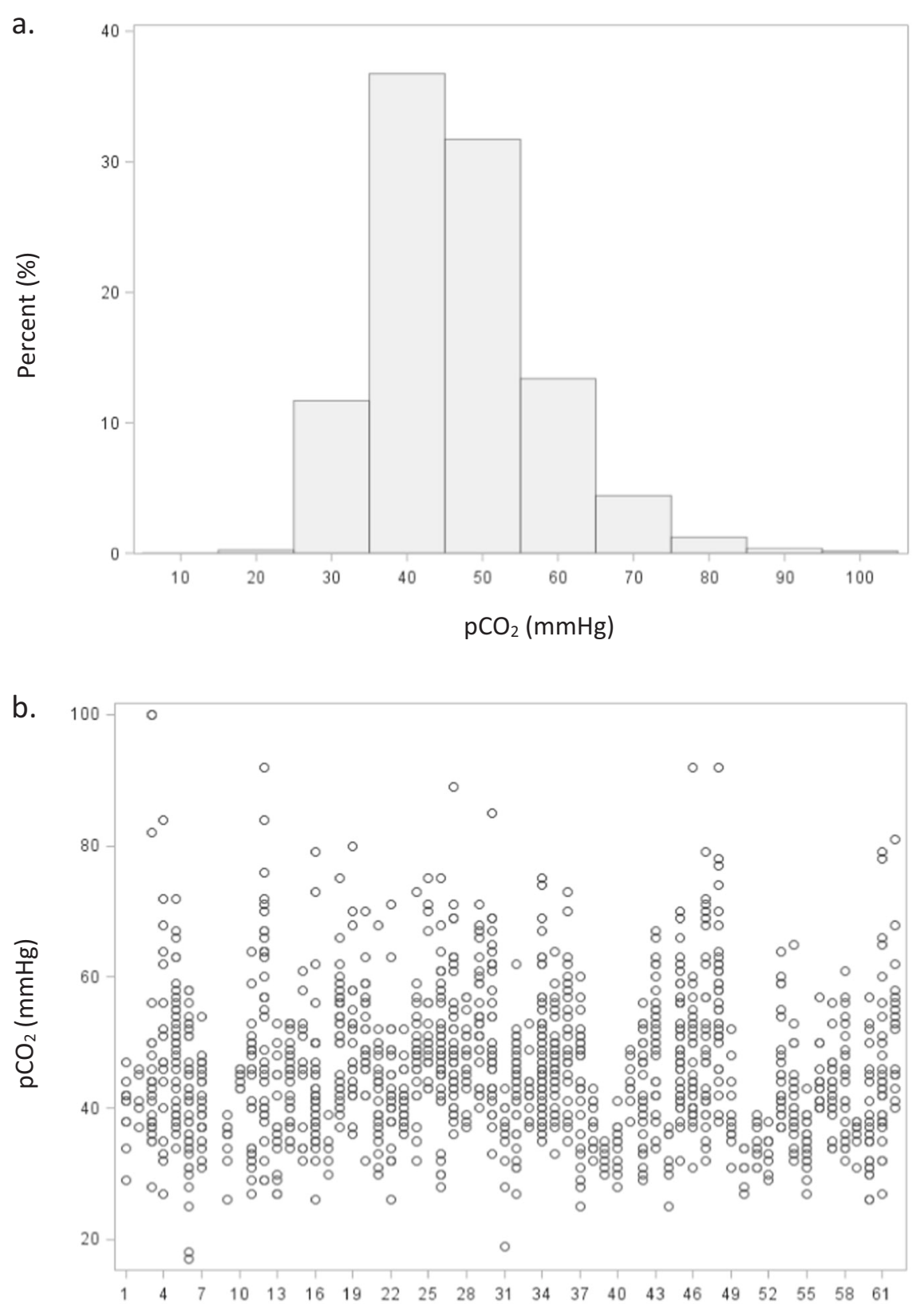

ID

$[2,11]$. Both studies were relatively small in number and utilized regression analysis to evaluate the autoregulatory relationship over a longer period of time. This methodology may be less sensitive in detecting activity in the lowfrequency bandwidth. In addition, these studies had fewer measurements on the first day of life than the current study. During this time, premature infants are more likely to have decreased cardiac output leading to decreased cerebral blood flow, potentially secondary to immature myocardium working against increased vascular resistance and high mean airway pressures used to support their respiratory status. In addition, we speculate that the mechanisms regulating vascular reactivity may be underdeveloped. These differences between our study and the previous studies may explain the differences in the results.

An overall lack of correlation between $\mathrm{pCO}_{2}$ mediated cerebrovascular reactivity and $\mathrm{CA}$ underscore that the vasoreactive effects of blood pressure and $\mathrm{pCO} 2$ changes are not well understood and may be mediated by distinct mechanisms [20]. A decreased $\mathrm{pH}$ due to increased $\mathrm{pCO}_{2}$ leads to blood vessel smooth muscle relaxation, while changes in the cerebrovasculature in response to blood pressure are mediated by myogenic mechanisms [21-23]. The relationship between these two regulatory mechanisms 


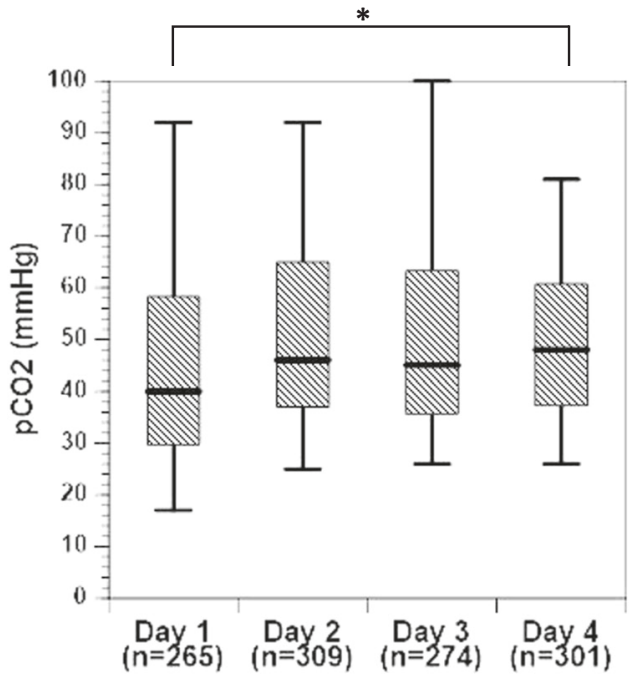

Fig. 2 Boxplot of the median, IQR, and range (black line, hashed box, and wiskers) $\mathrm{CO}_{2}$ by postnatal day. Asterisk (*) denotes a significant difference between postnatal days 1 and $4, p<0.0001$.

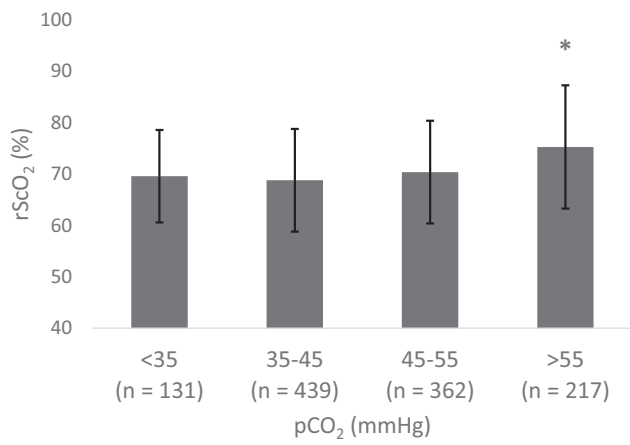

Fig. 3 Mean $\mathrm{rScO}_{2} \pm \mathrm{SD}$ by $\mathbf{p C O}_{2}$ category. Asterisk (*) denotes $p<$ 0.001 when the $\mathrm{pCO}_{2}>55 \mathrm{mmHg}$ group was compared to each other $\mathrm{pCO}_{2}$ category controlling for postnatal day, gestational age, respiratory support, and mean airway pressure at the time of sampling.

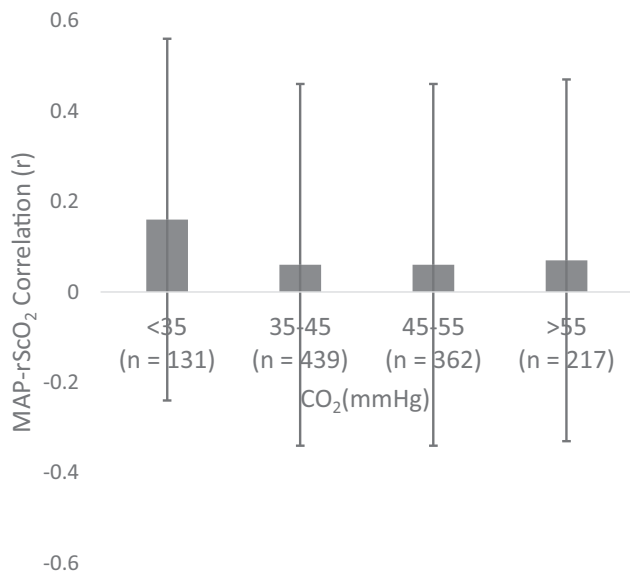

Fig. 4 Mean correlation between mean arterial blood pressure and $\mathrm{rScO}_{2}(r) \pm \mathrm{SD}$ by $\mathbf{p C O}_{2}$ category. There were no significant differences between groups. has been shown to be incredibly complex with one signal attenuating the other [24]. We speculate that this relationship would be even more complex in the setting of a premature infant undergoing transition from intrauterine to extrauterine life.

Even less well studied is the relationship between hypocapnia and CA. Hypocapnia is known to cause cerebral blood vessel vasoconstriction leading to decreased cerebral blood flow. In premature infants, hypocapnia has been associated with brain injury, decreased brain activity, and decreased cerebral oxygen saturation [25, 26]. Based on the current, though very limited, data, it has been hypothesized that hypocapnia may result in the CA plateau shifting downward to a lower cerebral blood flow without affecting the lower blood pressure threshold [24]. This, however, may not be the case in premature infants. In a study using complex mathematical modeling to estimate cerebral blood flow, the predicted CA curve noted pressure passive flow at low partial pressures of $\mathrm{pCO}_{2}$ [27], similar to what we noted on day 1 of life. We speculate that this could be secondary to the vasoconstrictive effects of low $\mathrm{pCO}_{2}$ in conjunction with a low cardiac output and cerebral blood flow on the first day of life leading to more pressure passive circulation when the $\mathrm{pCO}_{2}$ is low.

There are several limitations of this study that should be noted. A single center design may limit generalizability. Autoregulation analysis was on the lower bandwidth with a $0.03 \mathrm{~Hz}$ sampling rate and was dependent on the presence of an indwelling arterial line to continuously measure blood pressure. Given that the general practice in the NICU is to limit the use of invasive lines, this may self-select for a more critical population. In addition, respiratory management was provider dependent, though generally permissive hypercapnia $\left(\mathrm{pCO}_{2} 40-55 \mathrm{mmHg}\right)$ is allowed. Subjects with a higher severity of illness would have more blood gas measurements which may skew the data, although this was controlled for with mixed effects modeling that clustered at the subject level. In addition, we controlled for multiple potential confounders to address these potential concerns. We acknowledge that there are potential factors that may affect the $\mathrm{pCO}_{2}$-blood pressure-cerebrovascular reactivity relationship that may not have been accounted for. A lack of continuous $\mathrm{pCO}_{2}$ measurements limit the ability to determine a more sensitive temporal relationship and potential effects of $\mathrm{pCO}_{2}$ fluctuations on CA.

In conclusion, we have demonstrated that in premature neonates less than 29 weeks gestational age cerebral blood flow may be increased when $\mathrm{pCO}_{2}$ is greater than $55 \mathrm{mmHg}$ in the first 4 days of life, and autoregulation may be impaired at low levels of $\mathrm{pCO}_{2}$ on day of life one. This underscores the need for vigilant respiratory control especially on the first few days of life until the complex 
relationship between carbon dioxide, cerebral blood flow, and CA are better understood.

Funding This study is funded by the Mentored Population and Clinical Research Program of the American Heart Association, Award \#14CRP18140003 to SBH.

\section{Compliance with ethical standards}

Conflict of interest The authors declare that they have no conflict of interest.

Publisher's note Springer Nature remains neutral with regard to jurisdictional claims in published maps and institutional affiliations.

\section{References}

1. Jayasinghe D, Gill AB, Levene MI. CBF reactivity in hypotensive and normotensive preterm infants. Pediatr Res. 2003;54:848-53. http://www.ncbi.nlm.nih.gov/pubmed/12904589.

2. Noori S, Anderson M, Soleymani S, Seri I. Effect of carbon dioxide on cerebral blood flow velocity in preterm infants during postnatal transition. Acta Paediatr. 2014;103:e334-9. http://www. ncbi.nlm.nih.gov/pubmed/24673183.

3. Pryds O, Greisen G, Skov LL, Friis-Hansen B. Carbon dioxiderelated changes in cerebral blood volume and cerebral blood flow in mechanically ventilated preterm neonates: comparison of near infrared spectrophotometry and 133Xenon clearance. Pediatr Res. 1990;27:445-9. http://www.ncbi.nlm.nih.gov/pubmed/2161099.

4. Hoffman SB, Cheng YJ, Magder LS, Shet N, Viscardi RM. Cerebral autoregulation in premature infants during the first $96 \mathrm{~h}$ of life and relationship to adverse outcomes. Arch Dis Child Fetal Neonatal Ed. 2018. http://www.ncbi.nlm.nih.gov/pubmed/ 30385514.

5. Soul JS, Hammer PE, Tsuji M, et al. Fluctuating pressurepassivity is common in the cerebral circulation of sick premature infants. Pediatr Res. 2007;61:467-73. http://www.ncbi.nlm.nih. gov/pubmed/17515873.

6. Alderliesten T, Lemmers PM, Smarius JJ, van de Vosse RE, Baerts W, van Bel F. Cerebral oxygenation, extraction, and autoregulation in very preterm infants who develop periintraventricular hemorrhage. J Pediatr. 2012. http://www.ncbi. nlm.nih.gov/pubmed/23140883.

7. O'Leary H, Gregas MC, Limperopoulos C, et al. Elevated cerebral pressure passivity is associated with prematurity-related intracranial hemorrhage. Pediatrics. 2009;124:302-9. http://www.ncbi. nlm.nih.gov/pubmed/19564313.

8. Tsuji M, Saul JP, du Plessis A, et al. Cerebral intravascular oxygenation correlates with mean arterial pressure in critically ill premature infants. Pediatrics. 2000;106:625-32. http://www.ncbi. nlm.nih.gov/pubmed/11015501.

9. Gilmore MM, Stone BS, Shepard JA, Czosnyka M, Easley RB, Brady KM. Relationship between cerebrovascular dysautoregulation and arterial blood pressure in the premature infant. $\mathrm{J}$ Perinatol. 2011;31:722-9. http://www.ncbi.nlm.nih.gov/pubmed/ 21372795.

10. Brady KM, Lee JK, Kibler KK, et al. Continuous time-domain analysis of cerebrovascular autoregulation using near-infrared spectroscopy. Stroke. 2007;38:2818-25. http://www.ncbi.nlm.nih. gov/pubmed/17761921.
11. Kaiser JR, Gauss CH, Williams DK. The effects of hypercapnia on cerebral autoregulation in ventilated very low birth weight infants. Pediatr Res. 2005;58:931-5. http://www.ncbi.nlm.nih. gov/pubmed/16257928.

12. Vesoulis ZA, Mathur AM. Cerebral autoregulation, brain injury, and the transitioning premature infant. Front Pediatr. 2017;5:64. http://www.ncbi.nlm.nih.gov/pubmed/28421173.

13. Levene MI, Fawer CL, Lamont RF. Risk factors in the development of intraventricular haemorrhage in the preterm neonate. Arch Dis Child. 1982;57:410-7. http://www.ncbi.nlm.nih.gov/pubmed/ 7092304.

14. Dolfin T, Skidmore MB, Fong KW, Hoskins EM, Shennan AT. Incidence, severity, and timing of subependymal and intraventricular hemorrhages in preterm infants born in a perinatal unit as detected by serial real-time ultrasound. Pediatrics. 1983;71:541-6. http://www.ncbi.nlm.nih.gov/pubmed/6835737.

15. Ballabh $P$. Intraventricular hemorrhage in premature infants: mechanism of disease. Pediatr Res. 2010;67:1-8. http://www. ncbi.nlm.nih.gov/pubmed/19816235.

16. Thome UH, Ambalavanan N. Permissive hypercapnia to decrease lung injury in ventilated preterm neonates. Semin Fetal Neonatal Med. 2009;14:21-7. https://doi.org/10.1016/j.siny.2008.08.005.

17. Carlo WA, Stark AR, Wright LL, et al. Minimal ventilation to prevent bronchopulmonary dysplasia in extremely-low-birthweight infants. J Pediatr. 2002;141:370-5.

18. Mariani G, Cifuentes J, Carlo WA. Randomized trial of permissive hypercapnia in preterm infants. Pediatrics. 1999;104:1082-8.

19. Ryu J, Haddad G, Carlo WA. Clinical effectiveness and safety of permissive hypercapnia. Clin Perinatol. 2012;39:603-12.

20. Jeong SM, Kim SO, DeLorey DS, Babb TG, Levine BD, Zhang R. Lack of correlation between cerebral vasomotor reactivity and dynamic cerebral autoregulation during stepwise increases in inspired CO2 concentration. J Appl Physiol. 2016;120:1434-41. http://www.ncbi.nlm.nih.gov/pubmed/27103653.

21. Ainslie PN, Duffin J. Integration of cerebrovascular CO2 reactivity and chemoreflex control of breathing: mechanisms of regulation, measurement, and interpretation. Am J Physiol Regul Integr Comp Physiol. 2009;296:R1473-95. http://www.ncbi.nlm. nih.gov/pubmed/19211719.

22. Paulson OB, Strandgaard S, Edvinsson L. Cerebral autoregulation. Cerebrovasc Brain Metab Rev. 1990;2:161-92. http://www.ncbi. nlm.nih.gov/pubmed/2201348.

23. Zhang R, Zuckerman JH, Giller CA, Levine BD. Transfer function analysis of dynamic cerebral autoregulation in humans. Am J Physiol. 1998;274:H233-41. http://www.ncbi.nlm.nih.gov/ pubmed/9458872.

24. Meng L, Gelb AW. Regulation of cerebral autoregulation by carbon dioxide. Anesthesiology. 2015;122:196-205. http://www. ncbi.nlm.nih.gov/pubmed/25401418.

25. Dix LML, Weeke LC, de Vries LS, et al. Carbon dioxide fluctuations are associated with changes in cerebral oxygenation and electrical activity in infants born preterm. J Pediatr. 2017;187:66-72 e1. http://www.ncbi.nlm.nih.gov/pubmed/ 28578157.

26. Greisen G, Vannucci RC. Is periventricular leucomalacia a result of hypoxic-ischaemic injury? Hypocapnia and the preterm brain. Biol Neonate. 2001;79:194-200. http://www.ncbi.nlm.nih.gov/ pubmed/11275650.

27. Sidorenko I, Turova V, Botkin N, et al. Modeling cerebral blood flow dependence on carbon dioxide and mean arterial blood pressure in the immature brain with accounting for the germinal matrix. Front Neurol. 2018;9:812. http://www.ncbi.nlm.nih.gov/ pubmed/30356709. 